Article

\title{
The Potential of Pandanus amaryllifolius Leaves Extract in Fabrication of Dense and Uniform ZnO Microrods
}

\author{
Rabiatuladawiyah Md Akhir 1,2,*, Siti Zulaikha Umbaidilah 1,2, Nurul Afaah Abdullah 1,2, \\ Salman A.H. Alrokayan ${ }^{3}$, Haseeb A. Khan ${ }^{3}{ }^{1}$, Tetsuo Soga ${ }^{4}$, M. Rusop ${ }^{1,3,5}$ \\ and Zuraida Khusaimi ${ }^{1,5}$
}

1 NANO-SciTech Centre, Institute of Science, Universiti Teknologi MARA, Shah Alam 40450, Malaysia; zulaikhaumbaidilah95@gmail.com (S.Z.U.); afaahabdullah@yahoo.com (N.A.A.); zurai142@uitm.edu.my (Z.K.)

2 Faculty of Applied Sciences, Universiti Teknologi MARA, Shah Alam 40450, Malaysia

3 Research Chair for Biomedical Applications of Nanomaterials, Biochemistry Department, College of Science, King Saud University (KSU), Riyadh 11451, Saudi Arabia; salrokayan@ksu.edu.sa (S.A.H.A.); haseeb@ksu.edu.sa (H.A.K.)

4 Department of Frontier Materials, Nagoya Institute of Technology (NITech), Nagoya 466-8555, Japan; soga@nitech.ac.jp

5 NANO-Electronic Centre, Faculty of Electrical Engineering, Universiti Teknologi MARA, Shah Alam 40450, Malaysia; nanouitm@gmail.com

* Correspondence: rabiatul9581@uitm.edu.my; Tel.: +603-5544-4415

Received: 7 January 2020; Accepted: 20 February 2020; Published: 13 March 2020

\begin{abstract}
Zinc oxide $(\mathrm{ZnO})$ micro and nanorods were successfully prepared using Pandanus amaryllifolius and hexamethylenetetramine (HMTA) separately as stabilizers using the solution immersion method. Two types of $\mathrm{ZnO}$ seed layer were prepared using the same pre-cursor with the different stabilizers. The fabricated $\mathrm{ZnO}$ microrods exhibit absorption at $\sim 375 \mathrm{~nm}$ as revealed from the UV-Visible absorption spectrum, and this is comparable with $\mathrm{ZnO}$ nanorods synthesized using HMTA. X-ray diffraction (XRD) measurement displayed a sharp peak corresponding to the hexagonal wurtzite structure of $\mathrm{ZnO}$ microrods. Field emission scanning electron microscopy (FESEM) of $\mathrm{ZnO}$ microrods showed average diameter at approximately $500 \mathrm{~nm}$ compared to $70 \mathrm{~nm}$ of those synthesized from HMTA. A new finding is the ability of Pandanus amaryllifolius as a green stabilizer to grow a dense $\mathrm{ZnO}$ microrod structure with high crystallinity. Results reveal that both samples from different stabilizers during the preparation of the $\mathrm{ZnO}$ seed layer greatly improved the morphological and structural properties and optical absorption of $\mathrm{ZnO}$. The main outcomes from this study will benefit optoelectronic application, such as in ultraviolet (UV) sensors.
\end{abstract}

Keywords: zinc oxide (ZnO); nanorods; microrods; solution immersion method; green synthesis

\section{Introduction}

Recently, a high yield of zinc oxide ( $\mathrm{ZnO}$ ) nanostructures, using energy-efficient and cost-effective synthesis, has been preferred by various industries such as optoelectronics, photocatalytic, biomedical, agriculture, etc. This demand has led to a progressive synthesis method of $\mathrm{ZnO}$ nanostructures. In recent decades, $\mathrm{ZnO}$ nanostructures were mainly synthesized using combustion [1,2] and hydrothermal [3,4] methods. However, the synthesis routes of these methods make use of a large number of chemicals and harsh reaction conditions that contribute to environmental contaminants in the form of high energy consumption, heat generation, water consumption, and chemical waste $[5,6]$. In the following 
years, sol-gel process became an attractive approach due to its facile and low-cost method $[7,8]$. The method has been improvised using a sonication-assisted process, which gave advantages towards the elimination of agglomeration of the precursor solution [9]. Recently, the synthesis method has evolved towards a greener approach, such as the solution immersion method, which mostly uses hexamethylenetetramine (HMTA) as a stabilizer. This stabilizer is water-soluble, and the waste can be easily thrown away. However, we noticed that HMTA produced an unpleasant odor and therefore has room for improvement. As an alternative to these conventional chemical and physical methods, there is tremendous progress in the synthesis of nanostructures by using plant-mediated synthesis as reported by the literature.

Silver $(\mathrm{Ag})$ and gold $(\mathrm{Au})$ nanoparticles were among the first to be developed using plant extracts as reductants and stabilizing agents. The metals have been widely investigated for their high anti-microbial activity [10-12] and high photocatalytic reactivity [13,14]. Unfortunately, their production involves the use of expensive precursors. Metal oxides such as $\mathrm{ZnO}, \mathrm{TiO}_{2}$, and $\mathrm{SnO}_{2}$ can be an alternative to compete with the materials mentioned above and are suitable candidates due to their lower cost compared to Ag and Au. Among these semiconducting metal oxides, $\mathrm{ZnO}$ nanoparticles have received extensive attention due to their versatility in fabrication, which leads to unique morphological and structurally dependent physicochemical properties. In addition to that, $\mathrm{ZnO}$ also has an excellent anti-microbial activity [15-17] and other applications such as use in photocatalysis [18], gas sensors [19,20], and optoelectronics [21,22]. These biosynthesized ZnO nanoparticles exhibited equivalent properties as compared to those synthesized from the chemical and physical methods.

Recently, highly significant rod-shaped nanoparticles were successfully synthesized using leaves extract, and they possessed superior cellular penetration ability compared to other morphologies [23]. Related to this finding, Vishnukumar [24] reviewed the recent advances and emerging opportunities derived from plant-mediated synthesis for the fabrication of $\mathrm{ZnO}$ nanostructures. Almost all parts of plants from barks to seeds were utilized to aid in the synthesis of $\mathrm{ZnO}$ in nano forms. From this review, it can be understood that many studies have been conducted and have emphasized $\mathrm{ZnO}$ nanoparticle shape. However, $\mathrm{ZnO}$ nanostructures can be classified into many types based on their morphology such as nanorods, nanotubes, nanowires, nanoflowers, nanobelts, etc. Among these morphologies, nanorods were extensively studied for their excellent optical and electrical properties [25,26]. In the past few years, $\mathrm{ZnO}$ nanorods have risen as the best material for UV sensing usage [27]. This is owing to the superior surface area achieved with nanorods' diameters and densities [28,29]. However, no extensive studies have been performed in this direction, which dealt with the fabrication of $\mathrm{ZnO}$ nanorods by employing the phyto-assisted solution immersion method. Countless plant materials have yet to be explored for the synthesis of $\mathrm{ZnO}$ nanorods.

The importance of this study is the enhancement of crystallinity, size uniformity, and rod structure densities of $\mathrm{ZnO}$ at low immersion temperature. Using both the solution immersion and phyto-assisted solution immersion method results in a low-cost and environmentally friendly fabrication process. In this study, we report the potential of Pandanus amaryllifolius leaves extract as a green stabilizer in the production of $\mathrm{ZnO}$ nanostructures. We also compare $\mathrm{ZnO}$ nanostructures produced using hexamethylenetetramine (HMTA) as a stabilizer. Even though this green method may not substitute all the existing chemicals used, this is one of the ways to contribute towards lesser damage to the environment. To the best of our knowledge, the structural, morphological, and optical properties of $\mathrm{ZnO}$ microrods prepared using Pandanus amaryllifolius as a stabilizer via the phyto-assisted solution immersion method, yielding high crystallinity and high microrod density, have not yet been discussed elsewhere. We believe that $\mathrm{ZnO}$ nanorods with small diameter size, high nanorod densities, and high crystallinity can be obtained in our future research work and will be beneficial to optoelectronic applications such as UV sensors. 


\section{Materials and Methods}

\subsection{Preparation of Pandanus amaryllifolius Leaves Extract}

Fresh Pandanus amaryllifolius leaves were collected at a local farm and then thoroughly washed. They were then dried under the sun to ensure all remaining moisture was eliminated. The leaves were then finely cut. To prepare the extract for the synthesis of $\mathrm{ZnO}$ nanorods, $300 \mathrm{~g}$ of the leaves with $900 \mathrm{~mL}$ of deionized (DI) water were mixed and boiled at a temperature of $60{ }^{\circ} \mathrm{C}$ for $60 \mathrm{~min}$. The extract was cooled to room temperature and was filtered using filter paper before being stored in a refrigerator for further use. Figure 1 shows the preparation of Pandanus amaryllifolius extract.
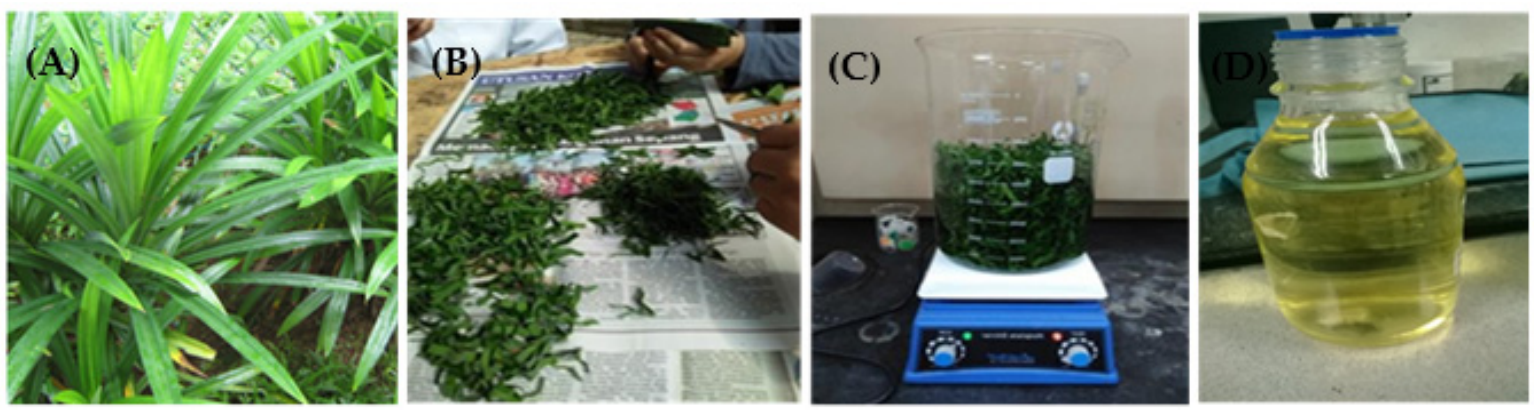

Figure 1. (A) Pandanus amaryllifolius leaves, (B) cutting process, (C) boiling process, (D) Pandanus amaryllifolius leaves extract.

\subsection{Preparation of $\mathrm{ZnO}$ Seed Layers}

The $\mathrm{ZnO}$ seed layers were prepared using zinc nitrate hexahydrate $\left.\left(\mathrm{Zn}\left(\mathrm{NO}_{3}\right)_{2} \cdot 6 \mathrm{H}_{2} \mathrm{O}\right), 0.4 \mathrm{M}\right)$ (Sigma-Aldrich, St. Louis, MO, USA) as a precursor dissolved in deionized water with Pandanus amaryllifolius leaves extract as a green stabilizer/reduction agent with ratio 1:2 (ZN/Pandan seed layer). A low concentration of $0.05 \mathrm{M}$ sodium hydroxide $(\mathrm{NaOH})$ was added dropwise until reaching $\mathrm{pH}$ 9 while stirring. After continuous stirring at $60^{\circ} \mathrm{C}$ for $2 \mathrm{~h}$, the sol was aged at room temperature for $24 \mathrm{~h}$. At this point, the precipitate was obtained and later was confirmed as $\mathrm{ZnO}$ nanostructures using field emission scanning electron microscopy (FESEM) analysis (FESEM; JEOL JSM 7600F, JEOL Ltd., Akishimi, Japan). On the other hand, the solution prepared was deposited on the glass substrate by the spin-coating method (Laurell Technologies Corporation, North Wales, PA, United States), as shown in Figure 2, at $6000 \mathrm{rpm}$ for $60 \mathrm{~s}$. Ten drops for each layer were then pre-heated for $10 \mathrm{~min}$ at $150{ }^{\circ} \mathrm{C}$. This process was repeated five times. After spin-coating the sol on the glass substrate, it was then annealed at $450{ }^{\circ} \mathrm{C}$ for $1 \mathrm{~h}$. To compare the effect between Pandanus amaryllifolius and HMTA on the growth of $\mathrm{ZnO}$ nanostructures, another $\mathrm{ZnO}$ seed layer also was prepared by using HMTA (the spin-coating method) as a stabilizer (Zn-HMTA seed layer) and underwent the same synthesis condition as the Zn-Pandan seed layer. 
(A)

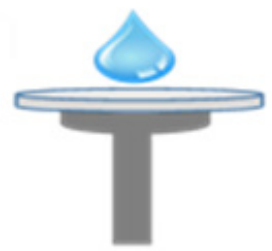

(C)

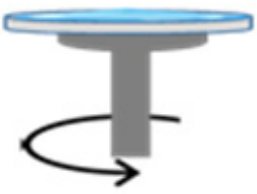

(B)

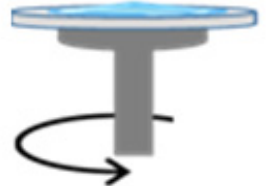

(D)

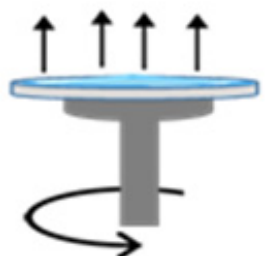

Figure 2. Spin coat process of (A) deposition, (B) initial spin, (C) final spin, and (D) evaporation.

\subsection{Preparation of $\mathrm{ZnO}$ Nanostructures}

The $\mathrm{ZnO}$ nanostructures were grown on both $\mathrm{Zn}$-Pandan and Zn-HMTA seed layers using the solution immersion method (Memmert GmbH + Co. KG, Schwabach, Germany) as shown in Figure 3. The solution was prepared by mixing $0.1 \mathrm{M} \mathrm{HMTA}$ and $0.1 \mathrm{M} \mathrm{Zn}\left(\mathrm{NO}_{3}\right)_{2} \cdot 6 \mathrm{H}_{2} \mathrm{O}$. The solution was mixed under continuous stirring at $60{ }^{\circ} \mathrm{C}$ for $2 \mathrm{~h}$ and was aged at room temperature for $24 \mathrm{~h}$ to get a clean and homogenous solution. The resulting solution was poured into a $50 \mathrm{~mL}$ centrifuge bottle.

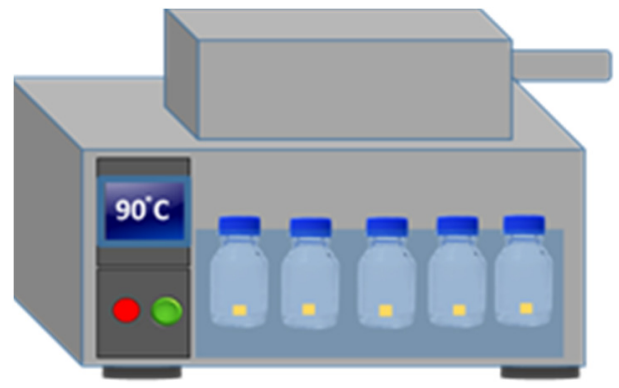

Figure 3. Solution immersion method.

The Zn-Pandan and Zn-HMTA seed layer-coated glass substrates were placed at the bottom of the centrifuge bottle. The centrifuge bottles were sealed and transferred to a water bath for $4 \mathrm{~h}$ at $90{ }^{\circ} \mathrm{C}$. After the immersion process, the samples were immediately taken out of the centrifuge bottle. The grown $\mathrm{ZnO}$ deposited on the Zn-Pandan and Zn-HMTA seed layer-coated glass substrates was cleaned by rinsing in deionized water and was dried in a furnace at $150{ }^{\circ} \mathrm{C}$ for 10 min. For grown $\mathrm{ZnO}$ on the $\mathrm{Zn}$-HMTA seed layer, its annealing temperature was controlled at $500{ }^{\circ} \mathrm{C}$ for $1 \mathrm{~h}$. This optimum annealing temperature has been established by other researchers especially in the solution immersion method [30-35]. ZnO nanorods prepared via the solution immersion method exhibited lower physicochemical properties when annealed at below a temperature of $500{ }^{\circ} \mathrm{C}$. However, no current references have been found on the synthesis of grown $\mathrm{ZnO}$ microrods on $\mathrm{Zn}$-Pandan seed layers using the solution immersion method. Hence, $\mathrm{ZnO}$ microrods on the $\mathrm{Zn}$-Pandan seed layer were annealed at different temperatures of $100,200,300,400$, and $500{ }^{\circ} \mathrm{C}$ to identify the optimum structural and optical properties as preliminary data for further morphological characterization.

\subsection{Characterization}

Crystal structure and phases of ZnO were investigated using PANalytical X'Pert Powder X-ray diffractometer (Malvern Panalytical Ltd., Malvern, UK) with a monochromatic $\mathrm{Cu} \operatorname{K} \alpha(\lambda=0.154 \mathrm{~nm})$. 
The crystallite size $(D)$ of the $\mathrm{ZnO}$ nanostructures was estimated by the Debye-Scherrer formula as in Equation (1):

$$
D=\mathrm{K} \lambda /(\beta \cdot \cos \cdot \theta)
$$

where:

$D=$ the crystal size;

$\lambda=$ the wavelength of the $X$-ray radiation $(\lambda=0.15406 \mathrm{~nm})$;

$\mathrm{K}=$ usually taken as 0.94 ;

$\beta=$ the full width at half maximum height;

$\theta=$ highest diffraction angle.

The optical properties of $\mathrm{ZnO}$ nanostructures were investigated by using an ultraviolet-visible model (Cary 60 UV-Vis, Santa Clara, CA, USA). A qualitative preliminary screening test (according to the standard method [36]) was used to examine the presence of secondary metabolic components in the extract of the leaves. To the best of our knowledge, the synthesis of $\mathrm{ZnO}$ microrods using Pandanus amaryllifolius as a stabilizer was reported for the first time. Hence, a preliminary study of structural and optical properties of $\mathrm{ZnO}$ microrods was investigated in order to select the optimum annealing temperature for further characterization. Morphology of $\mathrm{ZnO}$ microrods annealed at optimum annealing temperature was then characterized using a field emission scanning electron microscope (FESEM; JEOL JSM 7600F, JEOL Ltd., Akishimi, Japan) with an electron beam energy acceleration voltage of $3 \mathrm{kV}$.

\section{Results}

\subsection{X-Ray Diffraction (XRD)}

As a comparison with $\mathrm{ZnO}$ nanostructures using $\mathrm{Zn}$-Pandan seed layer, the X-ray diffraction (XRD) pattern of ZnO nanorods synthesized on Zn-HMTA seed layer was first carried out as a reference as shown in Figure 4. The samples exhibit sharp and strong diffraction peaks, which shows that the sample has a high degree of crystallinity. No other peaks were seen, suggesting no impurities other than pure $\mathrm{ZnO}$. It can be indexed as the hexagonal wurtzite structure (ref.code: 01-075-1526). The XRD pattern indicates that mostly three peaks appear at $2 \theta=32.07,34.42$, and 36.54, which corresponds to the (100), (002), and (101) crystallographic planes of $\mathrm{ZnO}$, respectively, and is in agreement with the result reported from previous literature [37,38].

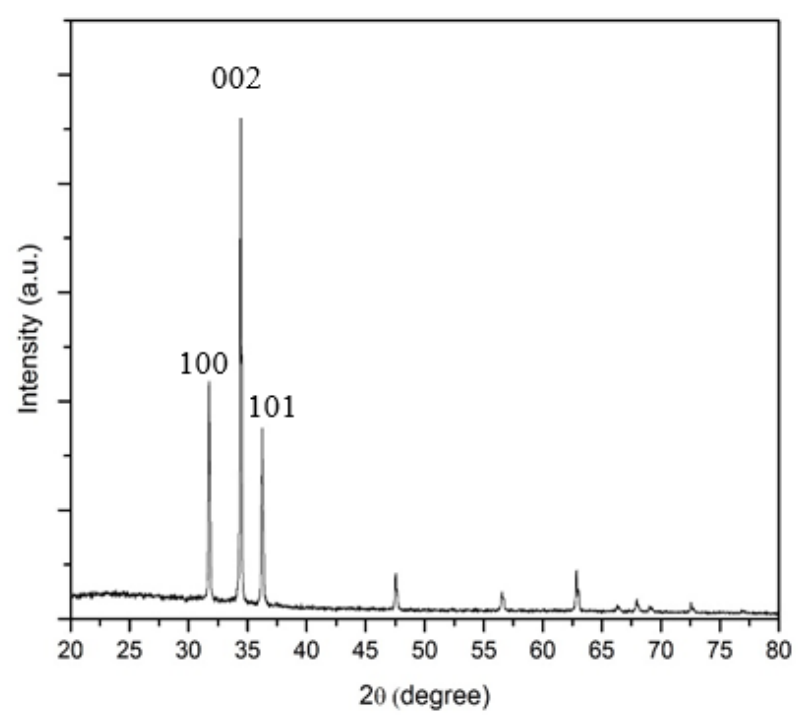

Figure 4. X-ray diffraction (XRD) pattern of ZnO nanorods on Zn-hexamethylenetetramine (HMTA) seed layer. 
It was found that the (002) peak is the most dominant, indicating that the nanostructured $\mathrm{ZnO}$ grows preferentially along the c-axis (perpendicular to the substrate) and formed nanorods structure. The other (100) and (101) peaks were due to the flower-like $\mathrm{ZnO}$ nanorods. It may be attributed to the excess of precursor $\left(\mathrm{Zn}\left(\mathrm{NO}_{3}\right)_{2} \cdot 6 \mathrm{H}_{2} \mathrm{O}\right)$ concentration (exceeding saturation limit) existing in the sample, leading to excessive growth rate of another $\mathrm{ZnO}$ rod on top of grown $\mathrm{ZnO}$ nanorods, and hence the formation of flower-like $\mathrm{ZnO}$ nanorods. Other than that, crystallographic peaks with weak intensities in the XRD spectra may be due to imperfect nanorod alignment on the substrate [39]. To qualify the preferred orientation of the obtained $\mathrm{ZnO}$ films, the relative intensity ratio $\mathrm{I}_{\mathrm{hkl}}$ is evaluated using Equation (2):

$$
\mathrm{I}_{\mathrm{hkl}}=\mathrm{I}_{\mathrm{hkl}} / \sum \mathrm{I}_{\mathrm{hkl}}
$$

where:

$\mathrm{I}_{\mathrm{hkl}}=$ hkl peak intensity;

$\sum \mathrm{I}_{\mathrm{hkl}}=$ sum of the intensities of all the diffraction peaks.

The relative intensity ratio of $\mathrm{I}_{(002)}$ of $\mathrm{ZnO}$ synthesized on $\mathrm{Zn}$-HMTA seed layer is 0.92 , which is significantly improved compared to that reported by [40] and [41]. On the other hand, Figure 5 shows the XRD pattern of $\mathrm{ZnO}$ nanostructures synthesized on $\mathrm{Zn}$-Pandan seed layer at temperatures of $100,200,300,400$, and $500{ }^{\circ} \mathrm{C}$. This sample also has a hexagonal wurtzite structure of $\mathrm{ZnO}$ (ref.code: 01-070-2551) and is randomly oriented as compared to the sample in Figure 4. The XRD pattern indicates that mostly three peaks appear at $2 \theta=31.78,34.47$, and 36.26, which corresponds to the (100), (002), and (101) crystallographic planes of $\mathrm{ZnO}$, respectively.

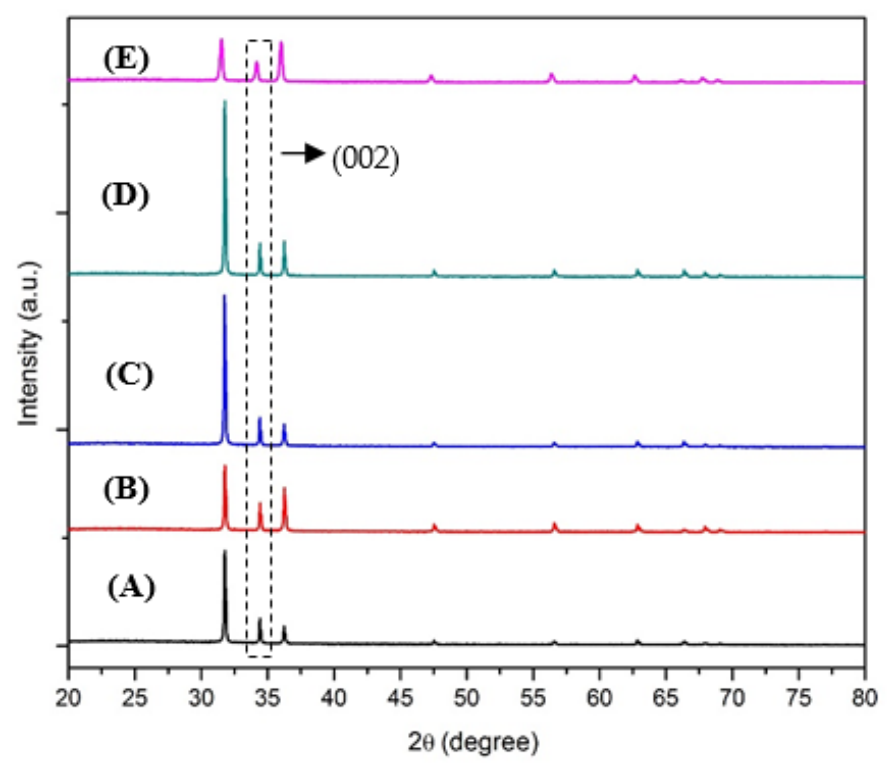

Figure 5. XRD pattern of ZnO microrods on Zn-Pandan seed layer annealed at: (A) 100, (B) 200, (C) 300, (D) 400 , and (E) $500{ }^{\circ} \mathrm{C}$.

It was found out that the (100) peak is dominant compared to (002) suggesting the formation of rod-like shape of nanoparticles is dominant compared to highly dense nanorods [36]. Other than that, these results also suggest that by using Pandanus amaryllifolius as stabilizer, pure $\mathrm{ZnO}$ can also be produced without other impurities. However, to obtain a nanorod morphology that is dominant at peak (002) remains challenging, as observed in Figure 5. The relative intensity of $\mathrm{I}_{(002)}$ of $\mathrm{ZnO}$ synthesized on the Zn-Pandan seed layer is 0.20 as evident in XRD spectra. This behavior is perhaps linked to the melting point of the phytochemical compounds in Pandanus amaryllifolius (flavonoids $273^{\circ} \mathrm{C}$ and phenols $40.5^{\circ} \mathrm{C}$ ). The solution containing mixed phytochemicals with one with a higher melting point and the other one with lower melting point has led to faster evaporation and forces 
the material to grow along other orientations. Overall, $\mathrm{ZnO}$ synthesized at annealing temperature of $400{ }^{\circ} \mathrm{C}$ exhibits the highest crystallinity compared to other samples. At $500{ }^{\circ} \mathrm{C}$, the crystallinity of $\mathrm{ZnO}$ suddenly decreased as it was beyond the melting point of the biomolecule compound (40 to $273^{\circ} \mathrm{C}$ ) in Pandanus amaryllifolius. The physicochemical properties of $\mathrm{Zn}$-Pandan seed layer annealed at $450{ }^{\circ} \mathrm{C}$ were compromised compared to those $\mathrm{ZnO}$ seed layers from conventional synthesis. Hence, excessive thermal energy was no longer recrystallized the sample; however, it disrupted the crystallinity. By using the Debye-Scherrer equation, the average crystallite size of $\mathrm{ZnO}$ nanostructures synthesized on the Zn-Pandan seed layer is equivalent $(11.23 \mathrm{~nm})$ to those sample synthesized from the Zn-HMTA seed layer (12.93 nm).

Figure 6 shows the XRD pattern of two different seed layers and grown $\mathrm{ZnO}$ on respective seed layers annealed at an optimum temperature. The $\mathrm{Zn}$-Pandan seed layer annealed at the same annealing temperature as the Zn-HMTA seed layer $\left(450^{\circ} \mathrm{C}\right)$ was found to have an amorphous structure. The bigger diameter size of grown $\mathrm{ZnO}$ on the $\mathrm{Zn}$-Pandan seed layer was affected by the amorphous structure of the $\mathrm{Zn}$-Pandan seed layer. As a comparison with other plant-based stabilizers in the synthesis of rod-shaped $\mathrm{ZnO}$ [36], our finding has shown consistent rod shape with a smaller crystallite size with higher crystallinity. As discussed previously in Section 1, higher crystallinity of $\mathrm{ZnO}$ is preferred for optoelectronics application, and this could be interesting as we can manipulate natural resources, which are highly abundant towards the synthesis of $\mathrm{ZnO}$ micro-nanorods with smaller crystallite size and highly crystalline at comparatively lower production cost. It also should be highlighted that this green alternative approach will benefit the environment as fewer solvents will be thrown away.

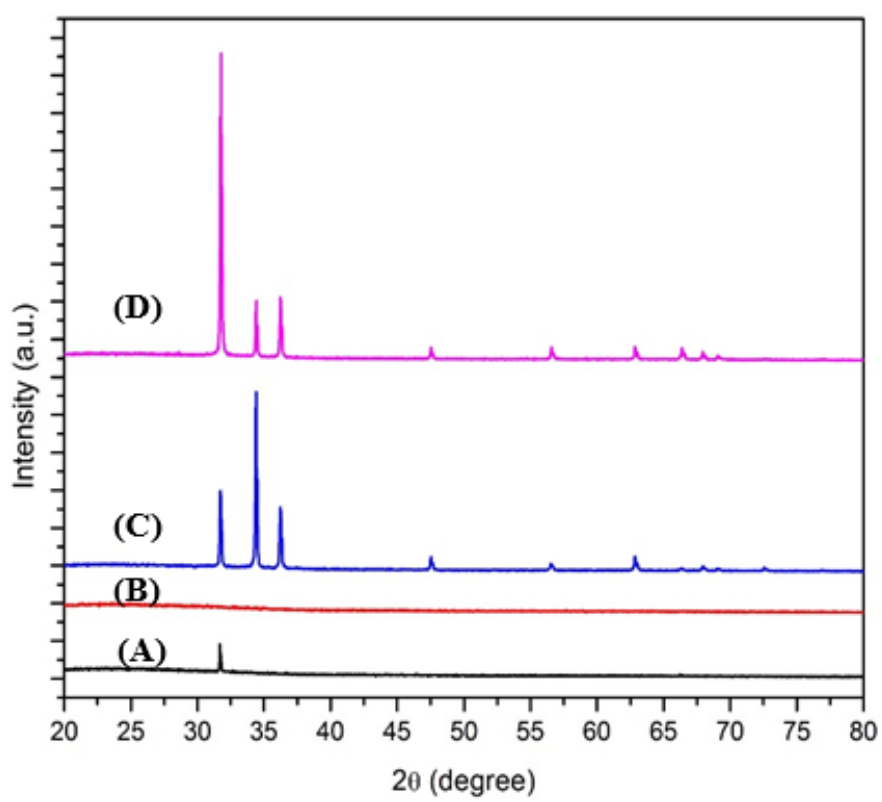

Figure 6. XRD pattern of (A) Zn-HMTA seed layer, (B) Zn-Pandan seed layer, (C) ZnO nanorods on $\mathrm{Zn}$-HMTA seed layer annealed at $500^{\circ} \mathrm{C}$, and (D) ZnO microrods on Zn-Pandan seed layer annealed at $400{ }^{\circ} \mathrm{C}$.

Another promising finding is that the crystallinity of $\mathrm{ZnO}$ microrods via the phyto-assisted solution immersion method in this study, as shown in Figure 5, was increased approximately six-fold compared to the synthesis of $\mathrm{ZnO}$ nanoparticles using Pandanus amaryllifolius leaves extract from sol-gel assisted precipitation method in the previous year [42]. This result verifies that plant-based stabilizers in general, and Pandanus amaryllifolius in particular, have played a significant in to the growth of $\mathrm{ZnO}$ and have potential to be a green alternative reducing and capping agent in the synthesis of highly crystalline $\mathrm{ZnO}$ nanostructures through progressive modifications and optimization. The essential ingredients 
in plant extracts such as terpenoids, alkaloids, phenols, and flavonoids play an important role in stabilizing and reducing and as capping agents in the formation of nanostructures. In various reports, phenols and flavonoids are involved in bio-reduction, stabilization, and formation of metal, metal oxide, and bimetallic nanoparticles. [43-45]. From this viewpoint, $\mathrm{ZnO}$ nanostructures synthesized from the Zn-Pandan seed layer at $400{ }^{\circ} \mathrm{C}$ were chosen to further characterize its morphology, since our aim was to achieve higher intensity of rod shape using the Zn-Pandan seed layer among the different annealing temperatures.

\subsection{Phytochemical Analysis}

Screening analysis for the presence of phytochemical contents in Pandanus amaryllifolius was carried out as preliminary data to confirm the role of Pandanus amaryllifolius as a stabilizer in the synthesis of $\mathrm{ZnO}$ nanorods. In this study, deionized water was used as the solvent for the extraction of plant metabolites, which were allowed to react with zinc nitrate hexahydrate solution. One of the advantages of this method is that mild solvents such as water, ethanol, or methanol also can be used as solvents to react with zinc salt solution under different conditions to obtain maximum yields [46-48] In general, plants contain metabolites such as tannins, terpenoids, saponins, starches, polypeptides, flavonoids, and phenols that act both as excellent reducing and capping agents. Screening for presence of flavonoid compounds in Pandanus amaryllifolius leaf extract was confirmed by using the Harbone method.

The results of the flavonoid test by using Pandanus amaryllifolius leaves extract are tabulated in Table 1. The "+" symbol is used to signify the presence of flavonoid in the leaves extract, which is responsible for the reduction of zinc ions to zinc metal. Pale yellow precipitates, yellow precipitates, and black precipitates were observed in the solution of lead II acetate, sodium hydroxide, and ferric chloride, respectively, after a few minutes. These results were in line with literature over the last year [36]. According to Basnet [49], biosynthesis of $\mathrm{ZnO}$ nanostructures is probably driven by the natural phytochemicals (like saponins, polyphenols, terpenoids), which act as both reducing as well as stabilizing (capping) agents. The phytochemicals initiate the reduction of the metal (zinc) to the 0 -valence state, and then through calcinations, the oxide may be added to the metal. Another very convincing mechanism is that zinc ions in the solution of the natural extract form complex ions with the polyphenols (or other phytochemicals). This is then followed by the formation of zinc hydroxide $\left(\mathrm{Zn}(\mathrm{OH})_{2}\right)$ through hydrolysis, and finally after calcinations, the complex decomposes, thereby favoring the formation of $\mathrm{ZnO}$ nanoparticles [50].

Table 1. Flavonoids test for Pandanus amaryllifolius leaves extract.

\begin{tabular}{ccc}
\hline Test & Observation & Result \\
\hline Lead acetate & Pale yellow precipitate & + \\
Sodium hydroxide & Deep yellow precipitate & + \\
Ferric chloride & Black precipitate & + \\
\hline "+" symbol is used to signify the presence of flavonoid in the leaves extract.
\end{tabular}

"+" symbol is used to signify the presence of flavonoid in the leaves extract.

In comparison with the previous methods for the synthesis of $\mathrm{ZnO}$ nanostructures, the precipitation method is the easiest and most widely employed. However, highly corrosive $\mathrm{NaOH}$ is often used as a reducing agent in the synthesis process. Based on Ul Haq [51], excessive amounts of $\mathrm{NaOH}$ with higher molar concentrations are always used to ensure reaction completion. Upon filtration of the reaction mixture, waste is discarded, which might go directly to the wastewater system. This could degrade the metallic parts of the sewage system and also alter the $\mathrm{pH}$ of water bodies causing hazards to aquatic flora and fauna. The utilization of Pandanus amaryllifolius extract as a reducing agent has minimized the volume of $\mathrm{NaOH}$ used in this study. The concentration used was very low (0.05 M) compared to that mostly reported by previous findings [52]. A few studies have attempted biological methods using plant extract as a reducing agent in the synthesis of $\mathrm{ZnO}$ nanostructures, especially nanorods. 
However, the morphology and particle size of $\mathrm{ZnO}$ nanorods produced from this phyto-assisted solution immersion method still need to be optimized in the near future.

\subsection{Ultraviolet-Visible (UV-Vis) Analysis}

A UV-Vis spectrometer was used to measure the absorption of the film in the range of 330-800 nm, as depicted in Figure 7. It showed comparatively strong excitonic absorption peaks at $375 \mathrm{~nm}$, which indicate the formation of $\mathrm{ZnO}$. This result is in line with results reported from previous literature [53]. In addition to that, these peaks indicated that the grown $\mathrm{ZnO}$ nanorods possessed good optical quality and large exciton binding energy [53]. The results showed that all samples exhibited high absorbance as annealing temperature increased from 100 to $400{ }^{\circ} \mathrm{C}$. This is due to the increase in absorption of photon energy with the increase in annealing temperature.
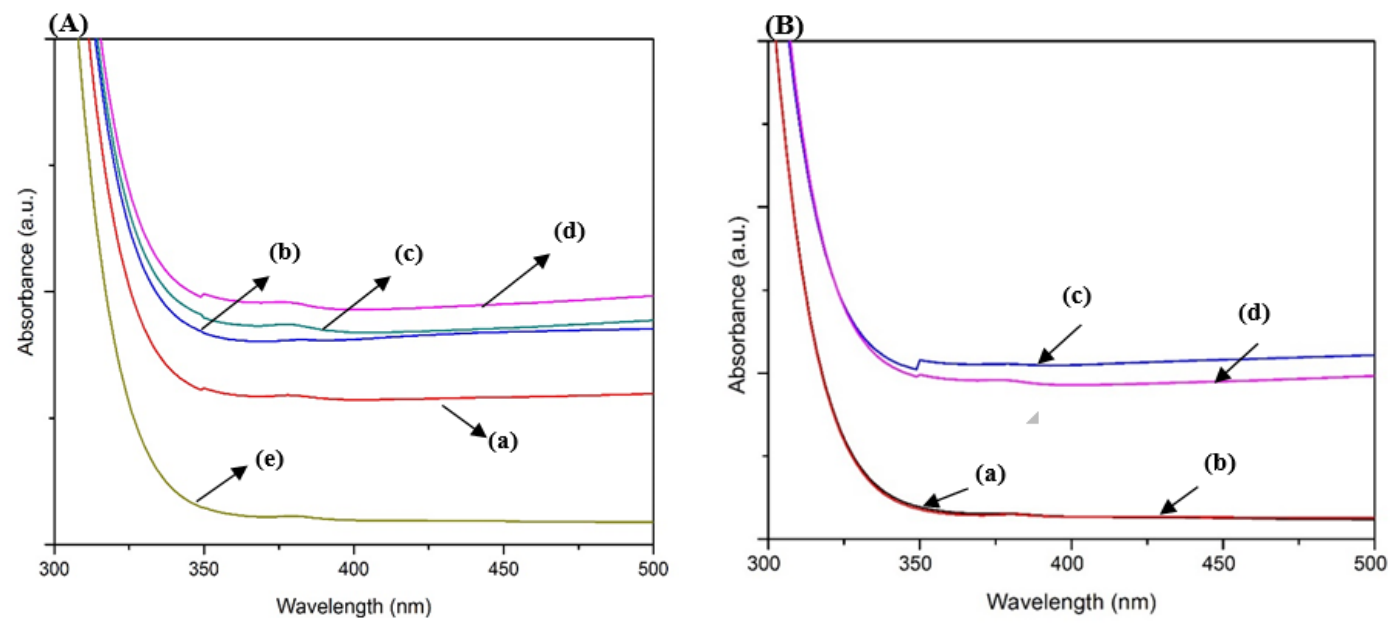

Figure 7. (A) UV-Vis absorbance of $\mathrm{ZnO}$ microrods on the $\mathrm{Zn}$-Pandan seed layer annealed at temperatures of (a) 100, (b) 200, (c) 300, (d) 400, and (e) $500{ }^{\circ} \mathrm{C}$. (B) UV-Vis absorbance of (a) Zn-HMTA seed layer, (b) Zn-Pandan seed layer, (c) ZnO nanorods on Zn-HMTA seed layer at $500{ }^{\circ} \mathrm{C}$, (d) $\mathrm{ZnO}$ microrods on $\mathrm{Zn}$-Pandan seed layer at $400{ }^{\circ} \mathrm{C}$.

From this result, it can also be inferred that optical properties of $\mathrm{ZnO}$ microrods synthesized on the Zn-Pandan seed layer can be comparatively equivalent to $\mathrm{ZnO}$ nanorods synthesized on the $\mathrm{Zn}$-HMTA seed layer. In addition, it is suggested that there was an enhancement in crystallinity of $\mathrm{ZnO}$ microrods on the Zn-Pandan seed layer as evident in the XRD pattern in Figure 5. UV-Vis spectra, however, show a dramatic decrease in absorption at an annealing temperature of $500{ }^{\circ} \mathrm{C}$. Excessive thermal energy given to the sample resulted in a higher number of defects formed in the sample annealed at high temperature. The $\mathrm{ZnO}$ growth on the $\mathrm{Zn}$-Pandan seed layer lost its crystallinity after being annealed at $500{ }^{\circ} \mathrm{C}$, as evident in Figure 5E. High temperature during the annealing process destructed some of the phytochemicals present in Pandanus amaryllifolius. Therefore, lower crystallinity is suspected to be a major cause of lower absorption compared to other samples. Figure 7B shows $\mathrm{UV}-\mathrm{Vis}$ absorbance of two different seed layers and grown $\mathrm{ZnO}$ on respective seed layers annealed at an optimum temperature. It was observed that absorbance of the Zn-Pandan seed layer was similar to the Zn-HMTA seed layer, which holds a potential in new green synthesis. The Zn-Pandan seed layer can be improved in terms of structural and morphological properties to achieve nanosized rod shape for future works. In conclusion, from XRD data and UV-Vis analysis, we chose sample ZnO (Zn-Pandan seed layer) synthesized at an annealing temperature of $400{ }^{\circ} \mathrm{C}$ to undergo morphology analysis by FESEM. 


\subsection{Field Emission Scanning Electron Microscopy (FESEM)}

Figure $8 \mathrm{~B}$ confirms that the formation of $\mathrm{ZnO}$ nanoparticles was produced using zinc nitrate and Pandanus amaryllifolius leaf extract. The results showed an average size of $\mathrm{ZnO}$ at $24.15 \mathrm{~nm}$, slightly smaller than that synthesized from HMTA, $30.54 \mathrm{~nm}$, as shown in Figure 8A. ZnO nanoparticles using Pandanus amaryllifolius as stabilizer exhibited similar nanostructure compared to using HMTA. This finding could be promising for manipulation of the phytochemical compound in Pandanus amaryllifolius in the reduction of zinc nitrate into zinc oxide and could help the stabilization process throughout the synthesis. Here, we combined the advantages of two types of nanostructures from the solution immersion method as shown in Figure 8. ZnO nanoparticles are favored for applications such as antimicrobial, corrosion, and photocatalytic application. On the other hand, $\mathrm{ZnO}$ nanorods have always been preferred for optoelectronic and gas sensor applications, as discussed in Section 1. As evident in Figure 8C, a dense and high uniformity of $\mathrm{ZnO}$ nanorods was produced using the $\mathrm{Zn}$-HMTA seed layer. Xu Yang [54] also used the ZnO seed layer for the formation of ZnO nanorods by a hydrothermal method. They found out that the bare $\mathrm{ZnO}$ nanorods are approximately in the shape of hexagonal prisms with their axes almost perpendicular to the substrate and having an average diameter of $90 \mathrm{~nm}$. Interestingly in our findings, through this simple and cost-effective solution immersion method, the hexagonal diameter becomes smaller with an average diameter of $71.67 \mathrm{~nm}$. In addition, the shape of the nanorods is denser and exhibits uniformity in size and shape. Inset of Figure 8C showes the flower-like shape of $\mathrm{ZnO}$ nanorods produced as evident from (100) and (101) peak in XRD pattern.

(A)

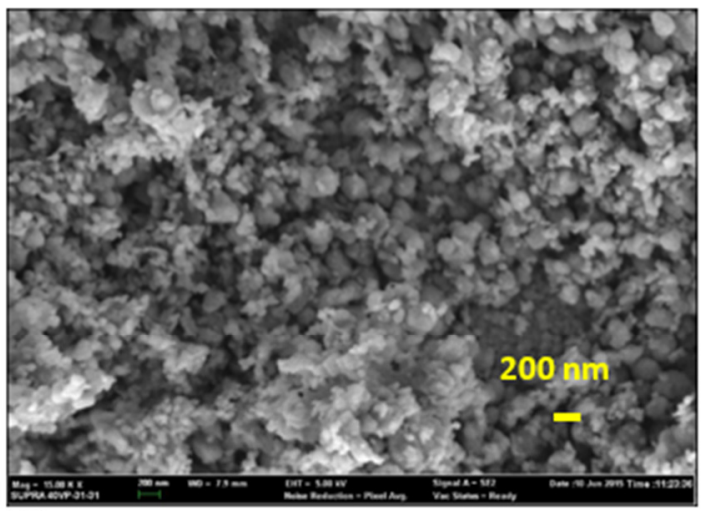

(C)

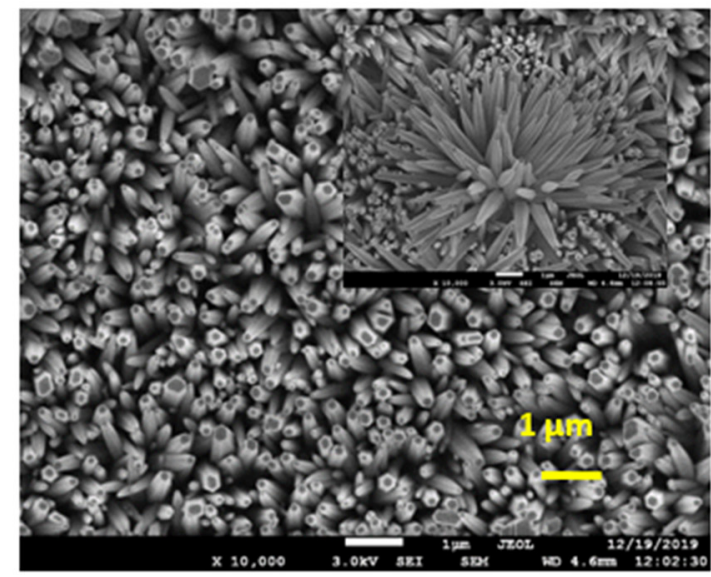

(B)

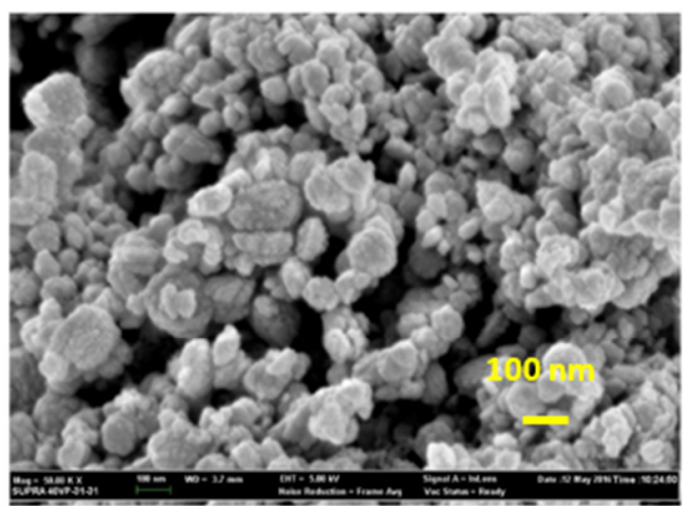

(D)

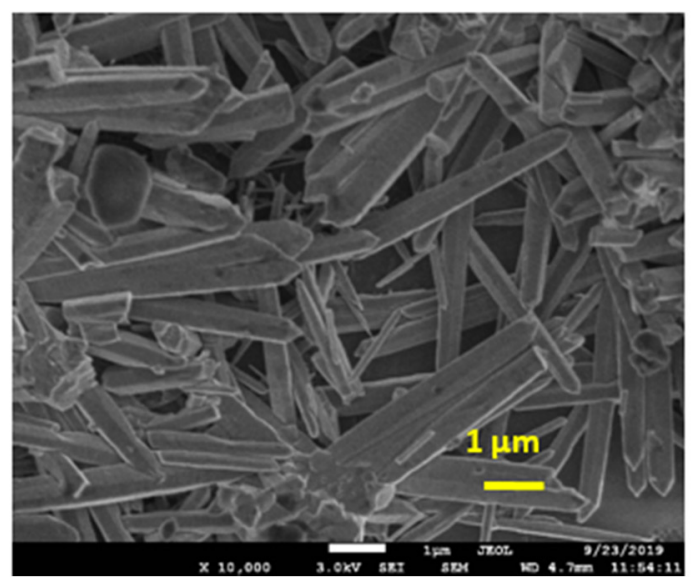

Figure 8. FESEM of (A) ZnO nanoparticles using Zn-HMTA, (B) ZnO nanoparticles using Zn-Pandan, (C) ZnO nanorods using Zn-HMTA seed layer, and (D) ZnO microrods using Zn-Pandan seed layer. 
We also synthesized $\mathrm{ZnO}$ microrods using the $\mathrm{Zn}$-Pandan seed layer to see the potential of Pandanus amaryllifolius as reducing/stabilizing agent in the synthesis of nanostructures. It is observed that when $\mathrm{ZnO}$ is grown on the $\mathrm{Zn}$-Pandan seed layer, the microrods are less hexagonal, and the diameter is increased to approximately $500 \mathrm{~nm}$. The solid structure of $\mathrm{ZnO}$ was formed from tightly bonded nanorods [55]. As observed in Figure 8D, even though the diameter size of $\mathrm{ZnO}$ microrods is bigger than that of $\mathrm{ZnO}$ nanorods in Figure $8 \mathrm{C}$, the shape and size uniformity are significant. The $\mathrm{Zn}$-Pandan seed layer is still able to produce $\mathrm{ZnO}$ without impurities and with dense microrod structures. The Zn-Pandan seed layer may not be conducive to growing smaller, more uniform, and denser $\mathrm{ZnO}$ nanorods due to the high annealing temperature of $450{ }^{\circ} \mathrm{C}$ of the $\mathrm{Zn}$-Pandan seed layer. This high energy force may degrade the functional groups that are responsible for stabilizing the zinc metal into monodispersed nanorods. From XRD, UV-Vis, and FESEM analysis, it was understood that $\mathrm{ZnO}$ nanorods synthesized from Zn-HMTA seed layer possessed better physicochemical properties compared to those synthesized from the Zn-Pandan seed layer. However, we also managed to highlight that this solution immersion method have potential to be easily tailored using green stabilizers with different annealing temperatures, which leads to a dense microrod structure and enhanced crystallinity compared to $\mathrm{ZnO}$ in nanoparticle shape. For future study, Zn-Pandan seed layer will be studied with emphasis given to the preparation of raw material (sun-dried, commercial-dried, and freeze-dried Pandanus amaryllifolius) to fine-tune optimum parameters to obtain $\mathrm{ZnO}$ rods in nano size.

\section{Conclusions}

In summary, we have successfully synthesized $\mathrm{ZnO}$ microrods on the $\mathrm{ZnO}$ seed layer using Pandanus amaryllifolius extract as a stabilizer and have compared with $\mathrm{ZnO}$ nanorods synthesized on the $\mathrm{ZnO}$ seed layer using HMTA as a stabilizer. The advantages of producing two different nanostructures through the phyto-assisted solution immersion method are reported for the first time. The (002) peak for ZnO microrods on Zn-Pandan seed layer and on Zn-HMTA seed layer were clearly confirmed by XRD. Both samples showed a hexagonal wurtzite crystal structure with high purity. Both ZnOs were further confirmed by UV-Vis at $\lambda_{\max }$ of $373 \mathrm{~nm}$. It was challenging to replicate exactly the same structural, optical, and morphological properties as obtained from $\mathrm{ZnO}$ nanorods on Zn-HMTA. However, the growth of $\mathrm{ZnO}$ microrods on the $\mathrm{Zn}$-Pandan seed layer is expected to achieve new changes in the field of UV sensors due to its dense and highly uniform microrod structures and high crystallinity using a local native plant (Pandanus amaryllifolius) as a cheaper and environmentally friendly stabilizer. These findings bridge the gap between conventional biosynthesis and the phyto-assisted solution immersion method and can be improved through a continuous parameter optimization process in the near future. Overall, the advantages of low working temperature, cheap raw materials, and most importantly, the least possible damage to the environment have added value to these findings.

Author Contributions: R.M.A. conceived the idea of experiment; R.M.A. and S.Z.U. performed the experiments; R.M.A., S.Z.U., N.A.A. discussed the results; R.M.A. wrote the manuscript; S.A.H.A., H.A.K. and T.S. funded the article processing charge; M.R. and Z.K. proofread and approved the final manuscript. All authors have read and agreed to the published version of the manuscript.

Funding: We would like to express our gratitude to Research Management Centre (RMC), Universiti Teknologi MARA, Malaysia through 600-IRMI/dana KCM 5/3/LESTARI (221/2017), for financial support. The authors are grateful to the Deanship of Scientific Research, King Saud University (KSU) for funding through Vice Deanship of Scientific Research Chairs.

Acknowledgments: The author gratefully acknowledges the Faculty of Applied Sciences and NANO-SciTech Laboratory, Universiti Teknologi MARA for providing the research facilities. Special thanks also to En. Salifairus Mohammad Jafar (UiTM Senior Science Officer), En. Mohd Azlan Jaafar (UiTM Assistant Engineer), Ts. Irmaizatussyehdany Buniyamin (UiTM Senior Research Officer), En. Abul Khamis Ishak (UiTM Science Officer) and Pn Hasdiyana Hashim (UiTM Science Officer) for their help and kind support to this research.

Conflicts of Interest: The authors declare no conflict of interest. 


\section{References}

1. Cao, Y.; Liu, B.; Huang, R.; Xia, Z.; Ge, S. Flash synthesis of flower-like ZnO nanostructures by microwaveinduced combustion process. Mater. Lett. 2011, 65, 160-163. [CrossRef]

2. Nehru, L.C.; Swaminathan, V.; Sanjeeviraja, C. Rapid synthesis of nanocrystalline ZnO by a microwaveassisted combustion method. Powder Technol. 2012, 226, 29-33. [CrossRef]

3. Kim, T.U.; Kim, J.A.; Pawar, S.M.; Moon, J.H.; Kim, J.H. Creation of nanoscale two-dimensional patterns of $\mathrm{ZnO}$ nanorods using laser interference lithography followed by hydrothermal synthesis at $90^{\circ} \mathrm{C}$. Cryst. Growth Des. 2010, 10, 4256-4261. [CrossRef]

4. Yun, S.; Lee, J.; Yang, J.; Lim, S. Hydrothermal synthesis of Al-doped ZnO nanorod arrays on Si substrate. Phys. B Condens. Matter 2010, 405, 413-419. [CrossRef]

5. Khoshhesab, Z.M.; Sarfaraz, M.; Asadabad, M.A. Preparation of ZnO nanostructures by chemical precipitation method. Synth. React. Inorg. Met. Chem. 2011, 41, 814-819. [CrossRef]

6. Udom, I.; Ram, M.K.; Stefanakos, E.K.; Hepp, A.F.; Goswami, D.Y. One dimensional-ZnO nanostructures: Synthesis, properties and environmental applications. Mater. Sci. Semicond. Process. 2013, 16, 2070-2083. [CrossRef]

7. Samat, N.A.; Nor, R.M. Sol-gel synthesis of zinc oxide nanoparticles using Citrus aurantifolia extracts. Ceram. Int. 2013, 39, S545-S548. [CrossRef]

8. Mamat, M.H.; Khusaimi, Z.; Musa, M.Z.; Sahdan, M.Z.; Rusop, M. Novel synthesis of aligned Zinc oxide nanorods on a glass substrate by sonicated sol-gel immersion. Mater. Lett. 2010, 64, 1211-1214. [CrossRef]

9. Badnore, A.U.; Pandit, A.B. Effect of $\mathrm{pH}$ on sonication assisted synthesis of $\mathrm{ZnO}$ nanostructures: Process details. Chem. Eng. Process. 2017, 122, 235-244. [CrossRef]

10. Ahmed, S.; Ahmad, M.; Swami, B.L.; Ikram, S. A review on plants extract mediated synthesis of silver nanoparticles for antimicrobial applications: A green expertise. J. Adv. Res. 2016, 7, 17-28. [CrossRef]

11. Raja, S.; Ramesh, V.; Thivaharan, V. Green biosynthesis of silver nanoparticles using Calliandra haematocephala leaf extract, their antibacterial activity and hydrogen peroxide sensing capability. Arab. J. Chem. 2017, 10, 253-261. [CrossRef]

12. Jain, S.; Mehata, M.S. Medicinal plant leaf extract and pure flavonoid mediated green synthesis of silver nanoparticles and their enhanced antibacterial property. Sci. Rep. 2017, 7, 15867. [CrossRef] [PubMed]

13. Khan, Z.U.H.; Khan, A.; Shah, A.; Wan, P.; Chen, Y.; Khan, G.M.; Khan, A.U.; Tahir, K.; Muhammad, N.; Khan, H.U. Enhanced photocatalytic and electrocatalytic applications of green synthesized silver nanoparticles. J. Mol. Liq. 2016, 220, 248-257. [CrossRef]

14. Elemike, E.E.; Onwudiwe, D.C.; Ekennia, A.C.; Ehiri, R.C.; Nnaji, N.J. Phytosynthesis of silver nanoparticles using aqueous leaf extracts of Lippia citriodora: Antimicrobial, larvicidal and photocatalytic evaluations. Mater. Sci. Eng. C 2017, 75, 980-989. [CrossRef]

15. Santhoshkumar, J.; Kumar, S.V.; Rajeshkumar, S. Synthesis of zinc oxide nanoparticles using plant leaf extract against urinary tract infection pathogen. Resour. Effic. Technol. 2017, 3, 459-465. [CrossRef]

16. Khan, S.A.; Noreen, F.; Kanwal, S.; Iqbal, A.; Hussain, G. Green synthesis of ZnO and Cu-doped ZnO nanoparticles from leaf extracts of Abutilon indicum, Clerodendrum infortunatum, Clerodendrum inerme and investigation of their biological and photocatalytic activities. Mater. Sci. Eng. C 2018, 82, 46-59. [CrossRef]

17. Sundrarajan, M.; Ambika, S.; Bharathi, K. Plant-extract mediated synthesis of ZnO nanoparticles using Pongamia pinnata and their activity against pathogenic bacteria. Adv. Powder Technol. 2015, 26, 1294-1299. [CrossRef]

18. Ong, C.B.; Ng, L.Y.; Mohammad, A.W. A review of ZnO nanoparticles as solar photocatalysts: Synthesis, mechanisms and applications. Renew. Sustain. Energy Rev. 2018, 81, 536-551. [CrossRef]

19. Zhao, Z.Y.; Wang, M.H.; Liu, T.T. Tribulus terrestris leaf extract assisted green synthesis and gas sensing properties of Ag-coated ZnO nanoparticles. Mater. Lett. 2015, 158, 274-277. [CrossRef]

20. Goutham, S.; Kaur, S.; Sadasivuni, K.K.; Bal, J.K.; Jayarambabu, N.; Kumar, D.S.; Rao, K.V. Nanostructured $\mathrm{ZnO}$ gas sensors obtained by green method and combustion technique. Mater. Sci. Semicond. Process. 2017, 57, 110-115. [CrossRef]

21. Singh, S.; Joshi, M.; Panthari, P.; Malhotra, B.; Kharkwal, A.C.; Kharkwal, H. Citrulline rich structurally stable zinc oxide nanostructures for superior photo catalytic and optoelectronic applications: A green synthesis approach. Nano Struct. Nano Objects 2017, 11, 1-6. [CrossRef] 
22. Çolak, H.; Karaköse, E.; Duman, F. High optoelectronic and antimicrobial performances of green synthesized ZnO nanoparticles using Aesculus hippocastanum. Environ. Chem. Lett. 2017, 15, 547-552. [CrossRef]

23. Jeevanandam, J.; San Chan, Y.; Ku, Y.H. Aqueous Eucalyptus globulus leaf extract-mediated biosynthesis of MgO nanorods. Appl. Biol. Chem. 2018, 61, 197-208. [CrossRef]

24. Vishnukumar, P.; Vivekanandhan, S.; Misra, M.; Mohanty, A.K. Recent advances and emerging opportunities in phytochemical synthesis of ZnO nanostructures. Mater. Sci. Semicond. Process. 2018, 80, 143-161. [CrossRef]

25. Ulianova, V.; Zazerin, A.; Pashkevich, G.; Bogdan, O.; Orlov, A. High-performance ultraviolet radiation sensors based on zinc oxide nanorods. Sens. Actuators A Phys. 2015, 234, 113-119. [CrossRef]

26. Dang, V.Q.; Trung, T.Q.; Duy, L.T.; Kim, B.Y.; Siddiqui, S.; Lee, W.; Lee, N.E. High-performance flexible ultraviolet (UV) phototransistor using hybrid channel of vertical ZnO nanorods and graphene. ACS Appl. Mater. Interfaces 2015, 7, 11032-11040. [CrossRef]

27. Mamat, M.H.; Malek, M.F.; Hafizah, N.N.; Khusaimi, Z.; Musa, M.Z.; Rusop, M. Fabrication of an ultraviolet photoconductive sensor using novel nanostructured, nanohole-enhanced, aligned aluminium-doped zinc oxide nanorod arrays at low immersion times. Sens. Actuators B Chem. 2014, 195, 609-622. [CrossRef]

28. Kar, J.P.; Das, S.N.; Choi, J.H.; Lee, Y.A.; Lee, T.Y.; Myoung, J.M. Fabrication of UV detectors based on ZnO nanowires using silicon microchannel. J. Cryst. Growth 2009, 311, 3305-3309. [CrossRef]

29. Kim, D.C.; Jung, B.O.; Lee, J.H.; Cho, H.K.; Lee, J.Y.; Lee, J.H. Dramatically enhanced ultraviolet photosensing mechanism in a n-ZnO nanowires/i-MgO/n-Si structure with highly dense nanowires and ultrathin $\mathrm{MgO}$ layers. Nanotechnology 2011, 22, 265506. [CrossRef]

30. Mohamed, R.; Khusaimi, Z.; Afaah, A.N.; Aziz, A.; Mamat, M.H.; Rusop, M. Effect of annealing temperature of magnesium doped zinc oxide nanorods growth on silicon substrate. J. Nano Res. 2014, 26, 33-38. [CrossRef]

31. Son, D.Y.; Bae, K.H.; Kim, H.S.; Park, N.G. Effects of seed layer on growth of ZnO nanorod and performance of perovskite solar cell. J. Phys. Chem. C 2015, 119, 10321-10328. [CrossRef]

32. Aziz, A.; Mohamed, R.; Afaah, A.N.; Asib, N.A.M.; Rusop, M.; Khusaimi, Z. Morphological and Optical Properties of Different Mg Percentage of $\mathrm{ZnO} / \mathrm{Mg}$ Thin Films Prepared by Sol-gel Spin-coating and Immersion Method. Adv. Mater. Res. 2015, 1107, 637-642. [CrossRef]

33. Mohamed, R.; Rouhi, J.; Malek, M.F.; Ismail, A.S.; Alrokayan, S.A.; Khan, H.A.; Khusaimi, Z.; Mamat, M.H.; Mahmood, M.R. Sol gel synthesized zinc oxide nanorods on single and Co-doped ZnO seed layer templates: Morphological, optical and electrical properties. Int. J. Electrochem. Sci. 2016, 11, 2197-2204.

34. Agarwal, M.B.; Sharma, A.; Malaidurai, M.; Thangavel, R. Effect of Sn doping on structural, mechanical, optical and electrical properties of $\mathrm{ZnO}$ nanoarrays prepared by sol-gel and hydrothermal process. Superlattices Microstruct. 2018, 117, 342-350. [CrossRef]

35. Asib, N.A.M.; Husairi, F.S.; Eswar, K.A.; Afaah, A.N.; Mamat, M.H.; Rusop, M.; Khusaimi, Z. Developing high-sensitivity UV sensors based on $\mathrm{ZnO}$ nanorods grown on $\mathrm{TiO}_{2}$ seed layer films using solution immersion method. Sens. Actuators A Phys. 2020, 302, 111827. [CrossRef]

36. Chennimalai, M.; Do, J.Y.; Kang, M.; Senthil, T.S. A facile green approach of ZnO NRs synthesized via Ricinus communis L. leaf extract for Biological activities. Mater. Sci. Eng. C 2019, 103, 109844. [CrossRef] [PubMed]

37. Kim, K.H.; Utashiro, K.; Abe, Y.; Kawwamura, M. Growth of zinc oxide nanorods using various seed layer annealing temperatures and substrate materials. Int. J. Electrochem. Sci. 2014, 9, 2080-2089.

38. Malek, M.F.; Mamat, M.H.; Soga, T.; Rahman, S.A.; Bakar, S.A.; Ismail, A.S.; Mohamed, R.; Alrokayan, S.A.; Khan, H.A.; Mahmood, M.R. Thickness-controlled synthesis of vertically aligned c-axis oriented ZnO nanorod arrays: Effect of growth time via novel dual sonication sol-gel process. Jpn. J. Appl. Phys. 2015, 55, 1.

39. Qiu, M.; Ye, Z.; Lu, J.; He, H.; Huang, J.; Zhu, L.; Zhao, B. Growth and properties of ZnO nanorod and nanonails by thermal evaporation. Appl. Surf. Sci. 2009, 255, 3972-3976. [CrossRef]

40. Mohammed, A.A.; Suriani, A.B.; Jabur, A.R. The enhancement Of UV sensor response by zinc oxide nanorods/reduced graphene oxide bilayer nanocomposites film. J. Phys. Conf. Ser. 2018, 1003, 012070. [CrossRef]

41. Bekkari, R.; Jaber, B.; Labrim, H.; Ouafi, M.; Zayyoun, N.; Laânab, L. Effect of Solvents and Stabilizer Molar Ratio on the Growth Orientation of Sol-Gel-Derived ZnO Thin Films. Int. J. Photoenergy 2019, 2019, 1-7. [CrossRef]

42. Akhir, R.M.; Norashikin, M.H.; Mahat, M.M.; Bonnia, N.N. Biosynthesis of Zinc Oxide Nanoparticles for Corrosion Protection Application. Int. J. Eng. Technol. 2018, 4, 488-492. 
43. Momeni, S.S.; Nasrollahzadeh, M.; Rustaiyan, A. Green synthesis of the $\mathrm{Cu} / \mathrm{ZnO}$ nanoparticles mediated by Euphorbia prolifera leaf extract and investigation of their catalytic activity. J. Colloid Interface Sci. 2016, 472, 173-179. [CrossRef] [PubMed]

44. Ahmed, S.; Chaudhry, S.A.; Ikram, S. A review on biogenic synthesis of ZnO nanoparticles using plant extracts and microbes: A prospect towards green chemistry. J. Photochem. Photobiol. B Biol. 2017, 166, $272-284$. [CrossRef] [PubMed]

45. Zikalala, N.; Matshetshe, K.; Parani, S.; Oluwafemi, O.S. Biosynthesis protocols for colloidal metal oxide nanoparticles. Nano Struct. Nano Objects 2018, 16, 288-299. [CrossRef]

46. Ingale, A.G.; Chaudhari, A.N. Biogenic synthesis of nanoparticles and potential applications: An eco-friendly approach. J. Nanomed. Nanotechol. 2013, 4,1-7. [CrossRef]

47. Makarov, V.V.; Love, A.J.; Sinitsyna, O.V.; Makarova, S.S.; Yaminsky, I.V.; Taliansky, M.E.; Kalinina, N.O. "Green" nanotechnologies: Synthesis of metal nanoparticles using plants. Acta Nat. 2014, 6, 35-44. [CrossRef]

48. Azizi, S.; Ahmad, M.B.; Namvar, F.; Mohamad, R. Green biosynthesis and characterization of zinc oxide nanoparticles using brown marine macroalga Sargassum muticum aqueous extract. Mater. Lett. 2014, 116, 275-277. [CrossRef]

49. Basnet, P.; Chanu, T.I.; Samanta, D.; Chatterjee, S. A review on bio-synthesized zinc oxide nanoparticles using plant extracts as reductants and stabilizing agents. J. Photochem. Photobiol. B Biol. 2018, 183, 201-221. [CrossRef]

50. Bala, N.; Saha, S.; Chakraborty, M.; Maiti, M.; Das, S.; Basu, R.; Nandy, P. Green synthesis of zinc oxide nanoparticles using Hibiscus subdariffa leaf extract: Effect of temperature on synthesis, anti-bacterial activity and anti-diabetic activity. RSC Adv. 2015, 5, 4993-5003. [CrossRef]

51. Naveed Ul Haq, A.; Nadhman, A.; Ullah, I.; Mustafa, G.; Yasinzai, M.; Khan, I. Synthesis approaches of zinc oxide nanoparticles: The dilemma of ecotoxicity. J. Nanomater. 2017, 2017, 1-14. [CrossRef]

52. Wang, J.; Ma, P.; Xiang, L. Effects of $\mathrm{NaOH}$ on formation of $\mathrm{ZnO}$ nanorods from $\varepsilon-\mathrm{Zn}(\mathrm{OH})_{2}$. Mater. Lett. 2015, 141, 118-121. [CrossRef]

53. Foo, K.L.; Hashim, U.; Muhammad, K.; Voon, C.H. Sol-gel synthesized zinc oxide nanorods and their structural and optical investigation for optoelectronic application. Nanoscale Res. Lett. 2014, 9, 429. [CrossRef] [PubMed]

54. Yang, X.; Li, H.; Zhang, W.; Sun, M.; Li, L.; Xu, N.; Wu, J.; Sun, J. High visible photoelectrochemical activity of Ag nanoparticle-sandwiched CdS/Ag/ZnO nanorods. ACS Appl. Mater. Interfaces 2017, 9, 658-667. [CrossRef] [PubMed]

55. Li, X.; Chen, X.; Yi, Z.; Zhou, Z.; Tang, Y.; Yi, Y. Fabriction of ZnO nanorods with strong UV absorption and different hydrophobicity on foamed nickel under different hydrothermal conditions. Micromachines 2019, 10, 164. [CrossRef]

(C) 2020 by the authors. Licensee MDPI, Basel, Switzerland. This article is an open access article distributed under the terms and conditions of the Creative Commons Attribution (CC BY) license (http://creativecommons.org/licenses/by/4.0/). 